\title{
Life cycle green-house gas emissions from power generation in China's provinces in 2020
}

\author{
Xin Li ${ }^{\mathrm{a}, \mathrm{b}, *}$ Konstantinos J. Chalvatzis ${ }^{\mathrm{a}, \mathrm{b}}$ Dimitrios Pappas ${ }^{\mathrm{a}, \mathrm{b}}$ \\ ${ }^{a}$ Norwich Business School, University of East Anglia, Norwich, NR4 7TJ, UK \\ ${ }^{b}$ Tyndall Centre for Climate Change Research, University of East Anglia, Norwich, NR4 7TJ, UK
}

\begin{abstract}
Carbon intensity of power generation is an important indicator to show the direct competitiveness of electricity against the combustion of fossil fuels. In this study, we estimate the carbon intensities of power generation in China's provinces. Most provinces are likely to have a carbon intensity per unit of power generation between 500 and 700 grams $\mathrm{CO}_{2} / \mathrm{kWh}$ in 2020, which justifies the progress of electrification from the power generation perspective. With the growing share of low carbon power generation, most provinces show trends of decline in carbon intensity between 2015 and 2020. However, some provinces are expected to see increase in carbon intensity due to increasing share of coal power generation in their power mixes. Coal is still a major growth contributor in most provinces, despite significant growths of low carbon energy sources. Furthermore, renewable energy sources can help reduce the carbon intensity of power generation, but a better coordination among provinces is required, alongside with strong government support and direction.
\end{abstract}

Keywords: carbon intensity; power generation; provinces in China

\footnotetext{
* Corresponding author. Tel: +44 01603-59-7390

E-mail address: x.li18@uea.ac.uk
} 


\section{Introduction ${ }^{1}$}

Low carbon electricity technologies have become more readily available from financial, technical and institutional perspectives. It has made electrification of the energy system a popular choice in the process of decarbonisation. Fossil fuels used for heating purposes and in transportation system can be replaced by electricity that is produced by renewables and other low carbon technologies, which in turn reduce $\mathrm{CO}_{2}$ emissions, changing the fuel mix without compromising security of supply [1-3]. Such transition would require electricity generation to be at least carbon emission competitive comparing to the conventional technologies, therefore the benefits of electrification can be justified.

In a previous study, Kennedy et al. [4] discuss the low-carbon infrastructure strategies for global cities. The authors argue that electrification of the transportation system can become carbon competitive once carbon intensity of power generation drops to 600 tonnes of $\mathrm{CO}_{2}$ equivalent $\left(\mathrm{CO}_{2}\right.$-e) per gigawatt hour (or 600 grams $\mathrm{CO}_{2}$-e per kilowatt-hour). In a following study, Kennedy [5] addresses the significance of achieving a short-term target of below 600 $\mathrm{g} / \mathrm{kWh}$ by 2020, which is essential to achieve the $2^{\circ} \mathrm{C}$ emission target in the longer term. Certainly, it is a short-term goal but it can be considered as a first step towards more ambitious targets of reducing $\mathrm{CO}_{2}$ emissions per unit of electricity by $90 \%$ by 2050 , as proposed by the IEA [6].

Since 1990, global average carbon intensity of electricity generation had been relatively stable varying between 506 and 546 grams $\mathrm{CO}_{2}$ per kWh (see Figure 1). However, there have been large variations in carbon intensity of power generation in different countries, influenced by a range of factors. Resource endowments and investment in these resources can affect the selection of power generation technology. Countries with significant hydropower potential can produce electricity of lower carbon intensity (such as Canada); by contrast, countries that have large fossil fuel reserves (such as oil in Saudi Arabia and coal in Australia) tend to produce electricity of higher carbon intensity. Equally, regions that face lack of availability of energy resources may choose to import forms of energy that are easily accessible but environmentally and financially damaging. At the same time, relevant government policies on energy and climate usually lead to a transition towards decarbonisation ${ }^{2}$. For example, the UK has introduced a carbon floor price [7], which is much higher than the price of EU ETS emission allowances. It has resulted in higher marginal costs for coal-fired stations than natural gas; therefore competitiveness loss. A significant decline in carbon intensity of power generation has happened in the UK. The country also introduced incentives to promote the conversion of existing coal-fired power plant to biomass (such as the case of Drax power station). Furthermore, demand growth can also affect technology selection. For countries with lower

\footnotetext{
${ }^{1}$ The short version of the paper was presented at ICAE2017, Aug 21-24, Cardiff, UK. This paper is a substantial extension of the short version of the conference paper.

${ }^{2}$ The revival of coal mining industry in the US and its associated environmental impacts is regarded as a special case.
} 
level of demand growth, building low-carbon intensive power technologies is capable to satisfy the demand. It is more convincing to phase out carbon intensive power plants and replace them with renewables when there is no demand growth pressure.

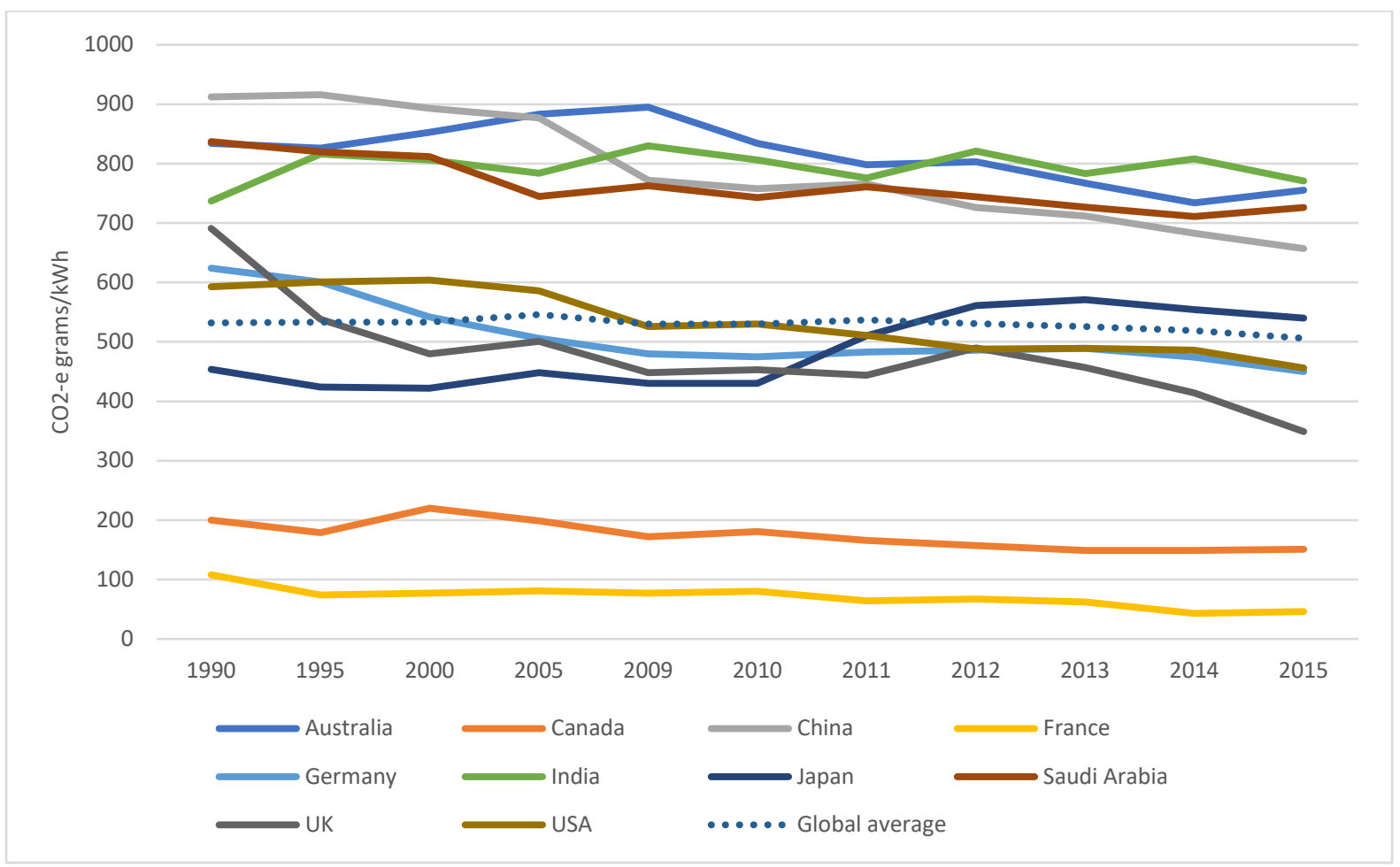

Figure 1: Carbon intensity of electricity generation in selected countries and at global average level

Source: [8]

As can be seen from Figure 1, China has shown a fast decline in carbon intensity of power generation, which had dropped to $657 \mathrm{CO}_{2} \mathrm{~g} / \mathrm{kWh}$ in 2015 from $912 \mathrm{CO}_{2} \mathrm{~g} / \mathrm{kWh}$ in 1990 [8]. Further reduction on carbon intensity per unit of power generation can be beneficial to China, since electrification has become an important component in China's energy transition. Fossil fuel combustion for heating, transportation and other purposes are not sustainable and need to be replaced with other technologies. There is no easy alternative within those areas, which makes electrification a popular choice $[9,10]$. Recent policies on China's electricity industry and its associated emission intensity has shown ambitious targets. For example, policy on controlling greenhouse gas (GHG) emissions in the $13^{\text {th }}$ Five-Year period has stated a target of electricity supply from major power generators to reach $550 \mathrm{~g} / \mathrm{kWh}$ [11]. However, historical data and recent trends in power supply emissions showed that even if a regional industrial shift occurs [12], the target may have overestimated the capability of achieving lower emission levels from China's power generation.

Furthermore, even though there are benefits in policy implementation through a central government [13] or a government controlled system [14] for a country as large as China, it is important to understand the carbon intensity in power generation at sub-national level. Power 
generation in China's provinces shows a large variation in terms of both volume and fuel mix. In 2015, for example, Shandong was the largest electricity-producing province. Its total power generation reached 461.9 TWh, with fossil fuels and wind power accounted for $97.6 \%$ and $2.1 \%$ of power supply respectively (the rest $0.3 \%$ was contributed equally by hydropower and solar power). Tibet is the smallest electricity-producing province with total power generation of 3.9 TWh. Hydropower dominated the supply mix, which accounted for $88.1 \%$ of the total production. The share of solar power was $6.2 \%$, which was ahead of all non-hydro energy sources (2.8\%) and fossil fuels (2.6\%). Moreover, resource endowments encourage the growth of renewable energy sources in some provinces [15]. By the end of 2015, Inner Mongolia had larger wind power capacity (24 GW) than Spain which at $23 \mathrm{GW}$ has the fifth largest wind capacity in the world. At the same time, five western and central provinces including Sichuan, Yunnan, Hubei, Guizhou and Guangxi accounted for over $70 \%$ of the total hydropower generation in China.

Understanding the future power mix and its emission intensity can be important to justify the transition towards electrification. This study estimates the carbon intensity of power generation by 2020 in China's provinces. A novel approach is used to include life cycle greenhouse gas emissions. The structure of this paper is organized as following: in Section 2, we introduce the background of China's power industry briefly with regards to the development plans during the thirteenth five-year period. Then, we introduce the data collection and the method to calculate carbon intensity in Section 3. Section 4 introduces the results of this study and Section 5 discuss the research findings. We conclude the study in Section 6.

\section{China's power industry in the thirteenth five-year period}

China's Five-Year Plans are a series of social and economic development initiatives. The most well-known five-year plan is the Five-Year Plan on Social and Economic Development [16], which provides general guidance for economic development, sets growth targets, and proposes reforms at the beginning of each five-year period, with the $13^{\text {th }}$ and last period being between 2016 and 2020. Alongside the economy-wide development, a number of supplementary plans are delivered by different government agencies, following the general guidance from the FiveYear Plan on Social and Economic Development.

Indeed, the $12^{\text {th }}$ five-year period (between 2011 and 2015) has been a cornerstone in China's power industry. Electricity demand growth has fallen to a record low level, particularly in 2014 and 2015, due to the economic rebalancing towards services-based and consumption-driven rather than industry development paths [17]. Even in this trajectory the role of electricity utilities in innovating for their end-users is paramount [18]. Average annual growth rate in electricity demand was 6.3\%. However, power generation capacity has still grown strongly. Total installed capacity increased from $970 \mathrm{GW}$ in 2010 to 1,530 GW in 2015, with an annual growth rate of 9.5\%. In particular, renewable energy sources such as wind and solar have shown quick expansion. Installed capacity of solar power increased from $0.3 \mathrm{GW}$ in 2010 to 42 GW in 2015 with an average annual growth rate of 169\%; wind capacity had quadrupled 
with an annual growth rate of 34\% (from $30 \mathrm{GW}$ to $131 \mathrm{GW}$ ). On the other hand, thermal power capacity (including coal, oil and gas, but mostly coal) had also increased from $710 \mathrm{GW}$ to $993 \mathrm{GW}$ with an annual growth rate of 6.9\% [19]. Although coal still dominate the power system, the share of low-carbon energy sources in China's power mix had been increasing significantly in the $12^{\text {th }}$ five-year period.

Stepping into the latest five year period, the $13^{\text {th }}$ Five Year Plan on Electricity System Development was announced by the National Development and Reform Commission and the National Energy Administration (NEA) in November 2016 [19]. It is the first national fiveyear plan on electricity system in the past 15 years, although broader energy five-year plans are available every five years. Akin to other five-year plans, the document identifies mediumterm binding or indicative targets and specifies measures to monitor the progress. Given the circumstances in China's power industry, the Plan delivers several main messages ${ }^{3}$ :

1) Related to coal-fired power generation, the plan states that the government 'strives to control the total coal capacity within 1,100 GW by 2020'. This is due to the fast expansion of coal capacity in the last couple of years that contribute to over-capacity. The plan also refers to the closure of $20 \mathrm{GW}$ of inefficient coal power plants between 2016 and 2020, which is very little by comparison to what is proposed to be built ${ }^{4}$. Furthermore, the target of coal consumption per unit of power generation is lowered to 310 grams $/ \mathrm{kWh}$ for existing coal power plants and 300 grams/kWh for newly built plants;

2) The total demand is projected between 6,800 and 7,200 TWh in 2020, which is based on a projected annual power demand growth between $3.6 \%$ and $4.8 \%$. The last few years have seen significant deceleration in demand growth. According to the IEA [20], the annual growth rates between 2000 and 2010 was above 12\%, comparing to 6\% between 2010 and 2016 (it was even slower between 2014 and 2016 at about 3.5\% on average).

3) The plan reveals generating capacity targets by 2020. Apart from the capacity target for coal, China plans to expand its power generation capacity with $110 \mathrm{GW}$ of gas power, 340 GW of hydropower, $210 \mathrm{GW}$ of wind power, $110 \mathrm{GW}$ of solar power and $58 \mathrm{GW}$ of nuclear power. Total non-fossil fuel capacity is expected to reach $770 \mathrm{GW}$, an increase of $250 \mathrm{GW}$ from 2015. It shows that China is moving away from fossil fuels and transitioning into renewable energy and other low carbon technologies. This clearly will lead to a reduction in carbon intensity per unit of power generation.

Besides, China also announced policies on controlling emissions from electricity generation. In December 2017, China launched its carbon emission trading scheme at national level. At the initial stage, emission quotas are limited only to power generation sector since the sector

\footnotetext{
${ }^{3}$ We introduce the key points in the Plan that are relevant to this study only. There are also many other important messages in the Plan, such as power system reform.

${ }^{4}$ Approximately $200 \mathrm{GW}$ of new coal power capacity is proposed between 2016 and 2020 (from around $900 \mathrm{GW}$ to $1,100 \mathrm{GW})$.
} 
has the largest amount of $\mathrm{CO}_{2}$ emissions and relatively complete emission data. Over 1,700 power generating companies are included, each of which have emissions over 26 thousand tonnes of $\mathrm{CO}_{2}$ equivalent emissions [21]. Similar to other carbon markets, policy makers set emission target levels and allocate carbon credits accordingly. Carbon credits can be purchased on carbon market from companies that have surplus credits when they emit less. Companies with higher emission levels will see increasing costs thus lower competitiveness. Therefore, the establishment of carbon market should have limited impacts on power supply but can encourage the improvement of efficiency [22]. Moreover, the State Council [11] also issued the $13^{\text {th }}$ Five Year Plan on Controlling Greenhouse Gas Emissions in October 2016. It states that 'all major power generating companies need to control their electricity supply emission levels at $550 \mathrm{~g} / \mathrm{kWh}$.' The target seems very ambitious, given the existing circumstances in China's power generation.

At sub-national level, several provinces have shown their $13^{\text {th }}$ Five-Year Plans on Energy Development (electricity-specific plan is rarely seen at provincial level; the Energy Development Plans instead covers a wide-range of electricity issues). Similar to national development plan, provincial development plans review the achievements in the previous five years, highlight development pathways in the next five years and specify measures to monitor the process. Given the large divergence in terms of economic development, resource endowments and energy consumption, provincial energy plans address the needs of domestic energy supply, which are largely different from one province to the other. For example, coastal areas are usually constrained by increasing air pollution thus addressing the needs of reducing coal power generation and encouraging the development of other energy sources. Interior regions, which are abundant in power supply, address the needs of developing transmission networks in order to export excessive electricity production to other provinces.

Nevertheless, all provincial energy development plans pursue wider electrification of the energy system. This includes the development of electric vehicle industry [23], the replacement of fossil fuel boilers with electric heaters and on the increased use of ICT equipment which has the potential to increase end user consumption [24, 25]. China is the largest electric vehicle market in 2016, which accounts for over $40 \%$ of the global electric vehicle sales [20]. The sales include 350,000 electric passenger vehicles and 35,000 electric buses. Provincial policies highlight the importance of electric vehicle in the transportation system during the $13^{\text {th }}$ fiveyear period. For example, Zhejiang introduces the $13^{\text {th }}$ Five Year Plan on EV and Charging Pile Development aiming at satisfying the need of charging 230,000 EVs by 2020. Beijing plans to upgrade charging infrastructure that can satisfy the electricity charging needs for 600,000 EVs by 2020, in the Beijing Electric Vehicle Charging Infrastructure Special Plan.

\section{Data and research method}

\subsection{Research Method}


Traditionally, carbon intensity of electricity generation is measured by summing GHG emissions resulted from the combustion of all energy sources (mostly fossil fuels, except biomass). Parameters such as net calorific value, carbon content and carbon oxidation factor are used to estimate total $\mathrm{CO}_{2}$ emissions from fuel combustion. For each energy source, there are usually more than 20 different fossil fuels covered in the estimation, depending on the database. Main categories include coal, oil and natural gas, which is split into sub-groups, such as raw coal, briquettes, liquefied natural gas and so on. Given the detailed data covered, it is difficult to project the consumption of all energy sources for power generation in the future.

In a previous study, Shearer et al. [26] estimate the annual emissions from coal power generation in India. Different from the approach above, the study estimate emissions through proposed/planned capacity in the future. Coal power capacity at different stage of development are collected (e.g. pre-permit, permitted, and under construction). Operating hours (represented by capacity factor) are adapted by using historical published data. Emissions per unit of power generation is calculated by multiplying heat rate (in BTU per $\mathrm{kWh}$ ) with emission factor (in pounds of $\mathrm{CO}_{2}$ per $\mathrm{BTU}$ ) and a coefficient (to convert pounds of $\mathrm{CO}_{2}$ to metric tonnes). However, similar to the approach above, this approach only takes into account direct emissions from the combustion of fossil fuels. Though direct emission accounts for a significant proportion of the total emissions, it does not capture upstream emissions (such as emissions related to coal mining and washing, plant construction, wind turbine manufacture, and solar panel manufacture) nor end-of-life emissions (i.e. emissions with regards to equipment disposal), which are not negligible.

In this study, we extend the method by Shearer and colleagues to estimate future carbon intensity of power generation from the life cycle perspective. In doing so, we focus on electricity generation only excluding activities designated for heat production.

For total life cycle GHG emissions from power generation in province $j$ represented by $E_{j}$, it can be calculated as

$$
E_{j}=\sum C_{j}^{i} * o p_{j}^{i} * e_{j}^{i}
$$

Where:

$C_{j}^{i}$ is the total generating capacity of energy type $i$ in province $j$ (in MW)

$o p_{j}^{i}$ is the estimated annual operating hours of energy type $i$ in province $j$ (in hours)

$e_{j}^{i}$ is the life cycle GHG emission factor of energy type $i$ in province $j$ (in $\mathrm{CO}_{2}$-e grams $/ \mathrm{kWh}$ )

For total power generation in province $j$, represented by $G_{j}$

$$
G_{j}=\sum C_{j}^{i} * o p_{j}^{i}
$$


The carbon intensity of power generation in province $j\left(C I_{j}\right)$ is then calculated as total life cycle GHG emissions from different power generation sources divided by the total power generation in each province as

$$
C I_{j}=\frac{E_{j}}{G_{j}}
$$

\subsection{Data source}

\subsubsection{Generating capacity at provincial level in 2020}

We compile data for power generation capacity at provincial level from different sources. The most important sources are the Thirteenth Five Year Energy Development Plans for each province. One of the main components of the provincial energy plans is to specify the capacity targets for power generation in the next five years, based on projected economic growth during the same period. Capacity targets are usually indicative, which means provincial governments do not bound to fulfil the targets. However, the targets can roughly represent the capacity level that will be constructed in the next five years. Not all energy sources are covered in the plans, depending on the provincial context. For example, some provinces around the coastal areas cover the development target for nuclear power (such as Fujian and Zhejiang). Other provinces in the western and central areas highlight the capacity targets for hydropower (such as Sichuan and Yunnan). Renewable energy capacity targets are most frequently addressed in provincial energy plans. For example, Hebei, Shanxi and Inner Mongolia provinces each propose to have $12 \mathrm{GW}$ of additional solar power capacity installed by 2020. For wind power, Inner Mongolia plans to add 27 GW of installed capacity, which is followed by Xinjiang (18 GW) and Hebei $(18 \mathrm{GW})$. The targets together with supporting policies (such as the technology-specific feedin-tariffs) are considered as the driving force of capacity growth, especially for renewable energy sources [20].

At the same time, we incorporate other data sources to complement the missing data in provinces which do not have relevant development plans. For example, for coal power, we use data from Endcoal [27] which lists the provincial coal power capacity under construction by July 2017. For nuclear power, we incorporate data from the World Nuclear Organization. It shows nuclear power plants that are due to become operational by 2020. For wind and solar power, we use the information from the national $13^{\text {th }}$ Five Year Development Plan for Wind Power and Solar Power, respectively [28]. These plans listed project generation capacity in each province. However, in some cases, the numbers do not coincide with the provincial development plans. We keep data from provincial plans since the energy governance has been kept mostly under the supervision of provincial authorities, which should be closer to reality. The aggregated power generation capacity at provincial level is close to the national plan (see Table 1). 
Table 1: A comparison of projected power generation capacity by 2020 (in GW)

\begin{tabular}{|lllllllll|} 
& Hydro & Coal & Natural Gas & Nuclear & Wind & Solar & Others & Total \\
\hline $\begin{array}{l}\text { National } \\
\begin{array}{l}\mathbf{1 3}^{\text {th }} \\
\text { Five-Year Plan }\end{array}\end{array}$ & 340 & 1,100 & 110 & 59 & 210 & 110 & 71 & 2,000 \\
\hline $\begin{array}{l}\text { Our estimation } \\
359\end{array}$ & 1,026 & 110 & 51 & 244 & 157 & 19 & 1,965 \\
\hline
\end{tabular}

Source: Own calculation, data from [19, 27, 28] and various provincial energy development plans

In general, our estimation is in line with the development targets in the $13^{\text {th }}$ Five-Year Plan, with total installed capacity reaching 1,965 GW comparing to the projected 2,000 GW. Coal capacity shows the largest difference. In our case, the 1,026 GW capacity is derived from the existing coal capacity in operation in addition to capacities under construction, as was given by Endcoal [27]. At the end of July 2017, the total capacity of coal power plants (larger than $30 \mathrm{MW}$ ) in operation and under construction amounts to $915 \mathrm{GW}^{5}$ and $147 \mathrm{GW}$, respectively. Given that the lead time of a coal power station construction is usually three to four years, we project that three-fourths of these capacities will be completed and become operational by 2020. For hydropower, the major difference comes from the accounting of pumped hydropower plants. At the end of 2015, total pumped hydro capacity was $23 \mathrm{GW}$, which is projected to reach $40 \mathrm{GW}$ by 2020, an addition of $17 \mathrm{GW}$. However, pumped hydro plants are included in the accounting of hydropower capacity in the Electric Statistical Yearbooks and are not readily separated from the main category since detailed pumped hydro capacities at provincial level are not available. Therefore, hydropower capacity in our estimation also includes pumped hydro. This has resulted in a lower figure in the 'Others' category. Furthermore, our estimation shows larger capacity for renewable energy sources such as wind and solar. In fact, the growth of renewable energy capacity largely exceeds the planned capacity. For example, solar PV capacity in 2016 reached $77 \mathrm{GW}$ with another $24.4 \mathrm{GW}$ being installed in the first half of 2017 [20], which made the total capacity reached over $100 \mathrm{GW}$. Therefore, the $110 \mathrm{GW}$ target in the $13^{\text {th }}$ five-year plan is very conservative. The same also applies to wind power capacity. Our estimation takes into account provincial development plans, which usually capture the provincial status quo better. Due to data availability, we do not consider Tibet in our estimation. Table S1 in Appendix gives the details of generation capacities for all power generation technologies in all provinces between 2011 and 2015.

\subsubsection{Operating hours for different power generation technologies}

Capacity data is converted to power generation by using the operating hours of each type of power generation technologies from each province. Operating hours is usually known as capacity factor which represents the ratio of actual electricity output over a given period to the maximum possible electricity output during that period. The full operation factor is based on

\footnotetext{
${ }^{5}$ The figure is different from statistics from the statistics from the NEA [30]. It shows a total capacity of 943 GW by the end of 2016. In order to make the numbers consistent (for plants in operation and under construction), we use the numbers from Endcoal to represent the coal fleet in China. To the best of our knowledge, no other source provides figures on coal plants under construction in China's provinces.
} 
the total hours in each year (8,760 hours). For example, if the capacity factor of a power plant is $40 \%$, it means the operating hours of this power plant is 3504 hours (8760*40\%). In a liberalised electricity market, capacity factor of a power plant depends on economic reasons (cost of generation), availability of the plant (equipment failure or maintenance) and resource availability (especially for renewable energy sources). Baseload plants, such as nuclear and coal, usually operate continuously at a certain level of output due to technical configuration and economic consideration (e.g. the energy penalty of quick ramping up and down). Natural gas plants are often used to provide ancillary services, therefore has lower level of capacity factor. Renewable energy sources outputs are variable subject to availability of wind and sunshine. Nevertheless, they are much lower than that of the baseload plants.

We calculate the operating hours for each power generation technology in each province between 2011 and 2015, by using the total power generation divided by the total installed capacity of each technology. There are large variations for different power generation technologies. We justify the choice of operating hours for each power generation technology as following.

Operating hours for coal power stations show declining trend since 2011. In 2015, the average operating hours were 4,207 hours, which represents a decline of 869 hours since $2011^{6}$. This is due to lower demand growth and development of other low carbon capacity during the period. However, electricity demand bounced back in 2016 and 2017, with annual growth rates at $5 \%$ and $6.6 \%$, respectively [29]. It has led to a revival of coal plant operating hours to a similar level in 2015 (4,209 hours). Policies that address the overcapacity of coal power in the last couple of years have shelved or cancelled the construction of over $200 \mathrm{GW}$ of coal capacity. The coal capacity data from Endcoal largely reflects such changes. If demand growths remain strong, we expect coal power to show a better performance in terms of operating hours in the next few years. This is to ensure sufficient power supply. For that reason, we use the average operating hours to estimate the total power generation for coal power.

The large-scale of curtailment of renewable energy output has resulted in a low operating hours for renewable energy. In 2016, for example, about $17 \%$ of total wind power generation at national level was curtailed due to limited flexibility of local power system and limited transmission capabilities among provincial and regional power grids. The curtailment rate is particularly high in resource-rich regions. Table 2 below shows the top 4 wind turbine owners and their associated levels of curtailment in 2016. Gansu has the highest curtailment rate of 43\% with the third largest wind power capacity of $12.8 \mathrm{GW}$. Xinjiang has third highest curtailment rate of 38\% with the second largest installed wind capacity of 17.8 GW in 2016 . After years of high curtailment, the Chinese government has announced policies to rectify the problem. For example, the National Energy Administration issued Measures for resolving curtailment of hydro, wind and PV power generation in November 2017 aiming at reducing

\footnotetext{
${ }^{6}$ All data before 2015 are based on various electric statistical yearbooks, unless specified otherwise.
} 
renewable energy curtailment through improved transmission channels and development of more flexible sources from both supply and demand side [30]. Together with the on-going power market reform, one should expect the better utilization of renewable energy sources. For that reason, we use the maximum operating hours for renewable energy sources (wind and solar).

Table 2: Top 4 wind power capacity provinces and associated curtailment rate in 2016

\begin{tabular}{|c|c|c|c|}
\hline Province & Capacity & Curtailment rate & Rank \\
\hline Inner Mongolia & $25.57 \mathrm{GW}$ & 21\% (12.4 TWh) & 3 \\
\hline Xinjiang & $17.76 \mathrm{GW}$ & 38\% (13.7 TWh) & 2 \\
\hline Gansu & $12.77 \mathrm{GW}$ & 43\% (10.4 TWh) & 1 \\
\hline Hebei & $11.88 \mathrm{GW}$ & $9 \%(2.2 \mathrm{TWh})$ & 8 \\
\hline
\end{tabular}

Source: [31]

Data for gas power is very limited. At national level, only total installed capacity and power generation are available. Although provincial energy development plans address the development of gas power, it will remain a minor contributor to the total power generation in these provinces with Beijing being the only exception. Beijing has phased out all its coal power plants since 2015. Electricity supply thereafter relies on gas and inter-provincial imports. It results in higher operating hours than the national average (4,459 vs 2,486 hours). Given the planned gas capacity in each province to total generating capacity, gas power is more likely to provide grid services than operating as a firm power supplier. Therefore, we use the national average figure to represent the operating hours for gas power in 2020.

For hydropower and nuclear power, average operating hours during 2011 and 2015 are used. Small adjustments are made for Guangxi and Hainan for nuclear power. In 2015, average operating hours for Guangxi were 642 hours and 615 hours for Hainan. This is due to the completion of new-built power plants being close to the end of the year. In 2016, the operating hours increased to 7,184 and 5,775 hours, respectively. Indeed, nuclear power plants usually operate with full operating loads as they do not have the flexibility to switch on and off frequently. Therefore, we use the 2015 operating hours of nuclear power in these two provinces and average operating hours for other provinces. Table S2 in Appendix gives the details of operating hours for all power generation technologies in all provinces.

In order to justify our choice of operating hours, we consider the projected electricity demand (between 6,800 and 7,200 TWh) by the $13^{\text {th }}$ Five-Year Plan on Electricity Development as a benchmark to ensure our estimation on generation is in line with demand. The projected electricity demand was based on an assumption that the annual demand growth would be between 3.6\% and 4.8\%. Demand growth in 2016 and 2017 has outpaced the projection. In our calculation, the total power generation is 7,260 TWh which is slightly above the upper limit set in the Plan. Therefore, our estimation on total power generation is close to the total power demand in 2020. This research does not address the changes of demand patterns, which represents the changes in socioeconomic conditions. Instead, we focus on the power generation fleet, which have been proposed by national and provincial governments. 


\subsubsection{Life cycle greenhouse gas emission factors}

The compilation of life cycle inventory can be complex. It requires detailed data inputs at all the stages of a product's life. To the best of our knowledge, only few studies address the issue in China at provincial level. For example, Ding et al. (2017) estimate life cycle energy consumption and GHG emissions from thermal power and solar power in China at provincial level. The study uses information on material requirements and emission coefficients from various sources. However, the study fails to distinguish different types of thermal power generation (e.g. coal, gas or oil), which have significant variations in terms of life cycle emissions. Another study by Feng et al. [32] estimate life-cycle $\mathrm{CO}_{2}$ emissions of 8 power generation technologies at national level, using a hybrid life cycle analysis ${ }^{7}$. Feng's results include the emissions from process life cycle analysis as well as the wider impacts via inputoutput analysis. This method has also been used in addressing the emission impacts of power generation in China [33, 34]. It shows that coal has significantly higher life cycle emissions per unit of power generation $(1,230 \mathrm{~g} / \mathrm{kWh})$, comparing to renewable energy sources (such as $46 \mathrm{~g} / \mathrm{kWh}$ for wind and $76 \mathrm{~g} / \mathrm{kWh}$ for solar). However, the study does not address the variations among China's provinces, focusing instead on the national average figure. In fact, the energy structure as well as the economic structure of China's provinces are largely different from the national average.

In this study we use the life cycle GHG emissions of seven power generation technologies provided in the most recent IPCC report [35] . It includes power generation from different sources, including coal, gas, hydro, nuclear, wind, solar and biomass. Summarizing results from previous literature, the IPCC report gives the maximum, medium and minimum values of GHG emissions during their life cycle [see Figure 2]. Since there is no better representatives that can reflect the life cycle GHG emissions at provincial level, the values are used in this study to represent the range of expected emissions. Two main GHG are included in the summary, namely $\mathrm{CO}_{2}$ and $\mathrm{CH}_{4}$. Some minor changes have been made to the values in hydropower generation, which shows a maximum value of life cycle GHG emissions per kWh at over 2000. As this is a special case in Brazil, we do not consider extreme values in our study.

${ }^{7}$ Hybrid life cycle analysis represent a combination of input-output analysis with process-based life cycle analysis. Process-based life cycle analysis captures the requirements of material use during a product' life cycle. However, it is restricted to the defined system boundary, which is often incomplete. Input-output analysis cover an economic system, which can be a region, country or the whole world. Therefore, the combination of process-based life cycle analysis with input-output analysis is considered as more accurate due to a complete system boundary. 


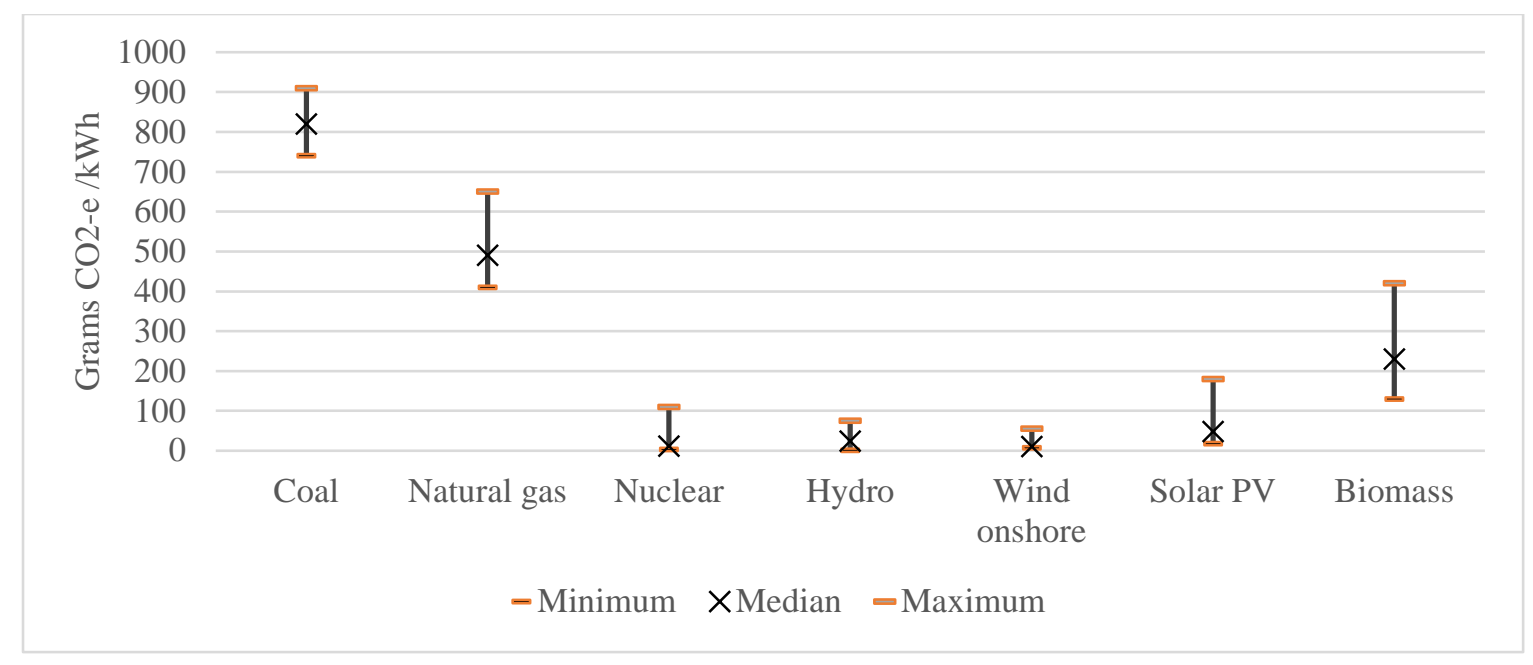

Figure 2: Emission factors for different power generation technologies at minimum, median and maximum levels Source: [35]

\section{Results}

\subsection{Carbon intensity by 2020 in China's provinces}

The electrification of transportation and the replacement of conventional boilers by equipment that is powered by electricity would require the carbon intensity of power generation to stay at 600 grams/kWh [36]. This target makes the transition towards electrification justified with lower emission level comparing to conventional technologies. Indeed, given the estimation uncertainties, the target is better represented by a range instead of a single value, which lies between 500 and $700 \mathrm{~g} / \mathrm{kWh}$. Figure 2 below shows our estimation of life cycle greenhouse gas emissions per unit of power generation in China's provinces and at national level. 


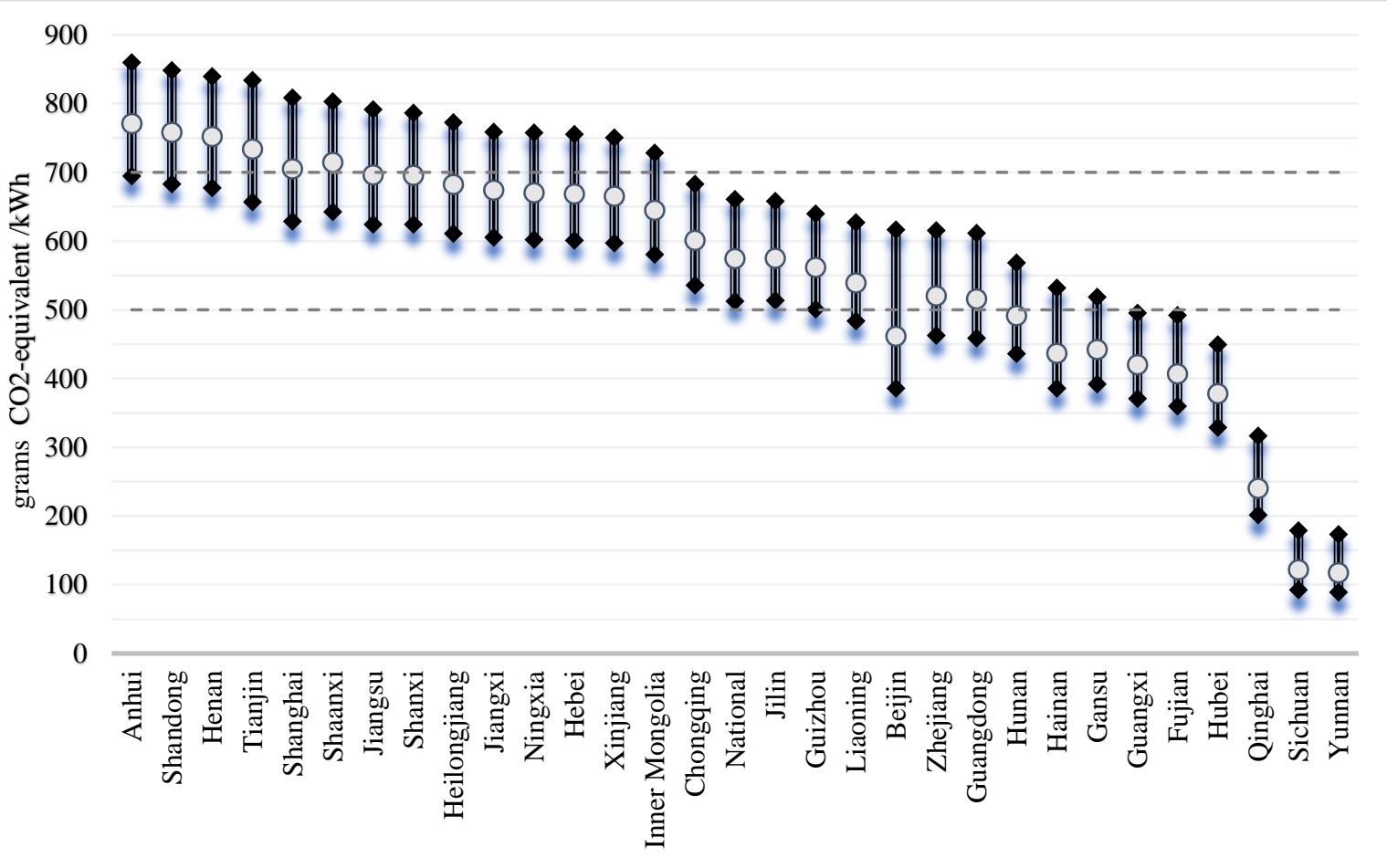

Figure 3: Life cycle GHG emissions per unit of power generation in China’s provinces by 2020

We show that China is on the trajectory to stay within the $500-700$ target range at national level in 2020. The possible range of carbon intensity lies between $500 \mathrm{~g} / \mathrm{kWh}$ under the minimum emission scenario and $661 \mathrm{~g} / \mathrm{kWh}$ under the maximum emission scenario, with medium carbon intensity level at $574 \mathrm{~g} / \mathrm{kWh}$ (the ranges are calculated based on the life cycle emission factors shown in Figure 2). The results are very close to the emission target set in the $13^{\text {th }}$ Five-Year Plan on Greenhouse Gas Emissions, which regulate carbon intensity of power generation from major power companies to stay within $550 \mathrm{~g} / \mathrm{kWh}$.

At provincial level, our results show that most provinces can or at least have the potential to stay within the range. The most influential factor in determining the carbon intensity of power generation in each province is the level of coal production (in terms of volume and its share of total production). Higher level of coal consumption in power generation leads to higher carbon intensity of power generation. Anhui shows the highest carbon intensity per unit of power generation in 2020, due to the large share of coal in its total power generation. In fact, the top three provinces such as Anhui, Shandong and Henan produce most of their power from coal (94\%, 91\% and 91\%, respectively), therefore showing higher level of emission intensity. Given the resource availability in these provinces, transition to a lower carbon intensity level is not straightforward. Nevertheless, these provinces still have the potential to stay within the $500-$ 700 grams/kWh range if the most energy efficient coal-fired units are used (e.g. under the minimum emission category). In fact, new coal power plants in China are more efficient than those of the US and the EU. Majority of the coal-fired plants were built after the 2000s. Therefore, higher energy efficiency can be expected. In addition, the carbon content in China's coal is lower than the international average [37], which means the combustion of same quantity 
of coal results in lower emissions. Despite the negative impacts on energy efficiency concerning the lower level of operation, there is potential for these provinces to achieve a lower level of emission intensity. Moreover, over half of China's provinces stay within the range and six of them are well below $500 \mathrm{~g} / \mathrm{kWh}$. The lowest four provinces including Hubei, Qinghai, Sichuan and Yunnan have abundant hydropower generation; thus, have very low level of carbon intensity in their power generation.

\subsection{Changes in emission intensity between 2015 and 2020}

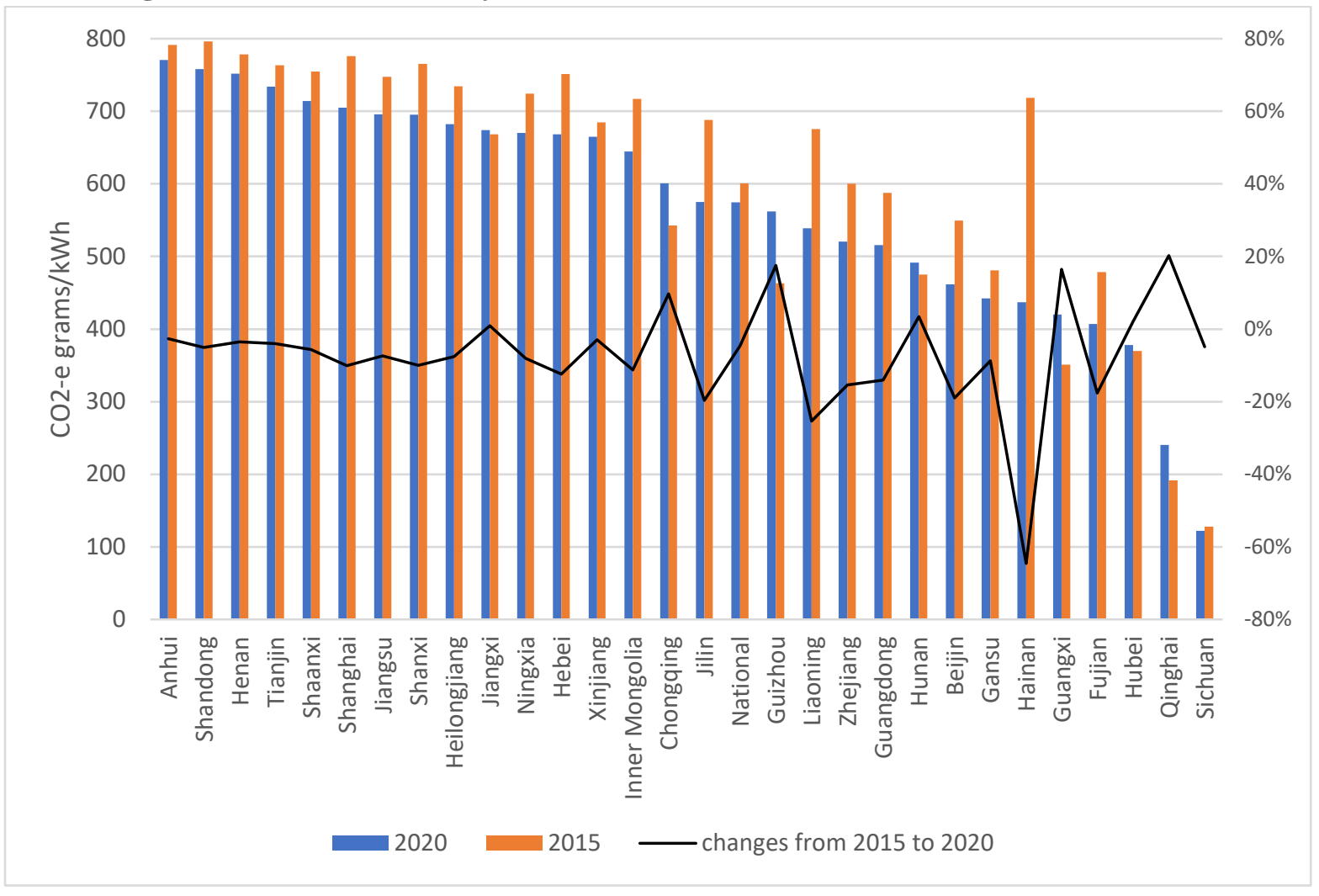

Figure 4: Carbon intensity of power generation in 2015 and 2020

We compare the carbon intensity at the medium level of emission intensity in different provinces (See Figure 4) in 2015 and 2020 and find significant variations in its trend. Most provinces show trends of decline in carbon intensity. For example, the carbon intensity of power generation is likely to decline by $65 \%$ in Hainan province (from $719 \mathrm{~g} / \mathrm{kWh}$ to 437 $\mathrm{g} / \mathrm{kWh}$ ), which is the largest decline among all provinces. The change is largely due to the growth of nuclear power and hydropower in the province. This makes the share of coal power in total power generation drop from $81 \%$ in 2015 to $46 \%$ in 2020 . At the same time, nuclear power accounts for $24 \%$ of total power generation in 2020 , comparing to $2 \%$ in 2015 . The contribution of hydropower to total power generation increase to $11 \%$, which is followed by natural gas at $10 \%$.

On the other hand, eight provinces show an increasing level of $\mathrm{CO}_{2}$ emissions per $\mathrm{kWh}$, including Jiangxi, Chongqing, Guizhou, Guangxi, Hubei, Qinghai, Sichuan and Yunnan. Half of these provinces still have low level of carbon intensity, even with increasing emission 
intensity. This is because of the significant hydropower generation in their power mix, which result in very low carbon intensity. With the possible expansion of coal fleet, these provinces have higher proportion of power generation from more carbon intensive energy sources. For example, Qinghai had 65\% of electricity supplied from hydropower in 2015, which is likely to drop to 55\% in 2020. With increasing share of coal in power generation (from 20\% in 2015 to $26 \%$ in 2020), Qinghai is likely to see an increase of $25 \%$ in its carbon intensity the largest increase in carbon intensity amongst all provinces. Nevertheless, the carbon intensity of power generation in Qinghai is still well below the $600 \mathrm{~g} / \mathrm{kWh}$ benchmark, sitting at $256 \mathrm{~g} / \mathrm{kWh}$.

\subsection{Growth of each power generation technology between 2015 and 2020}

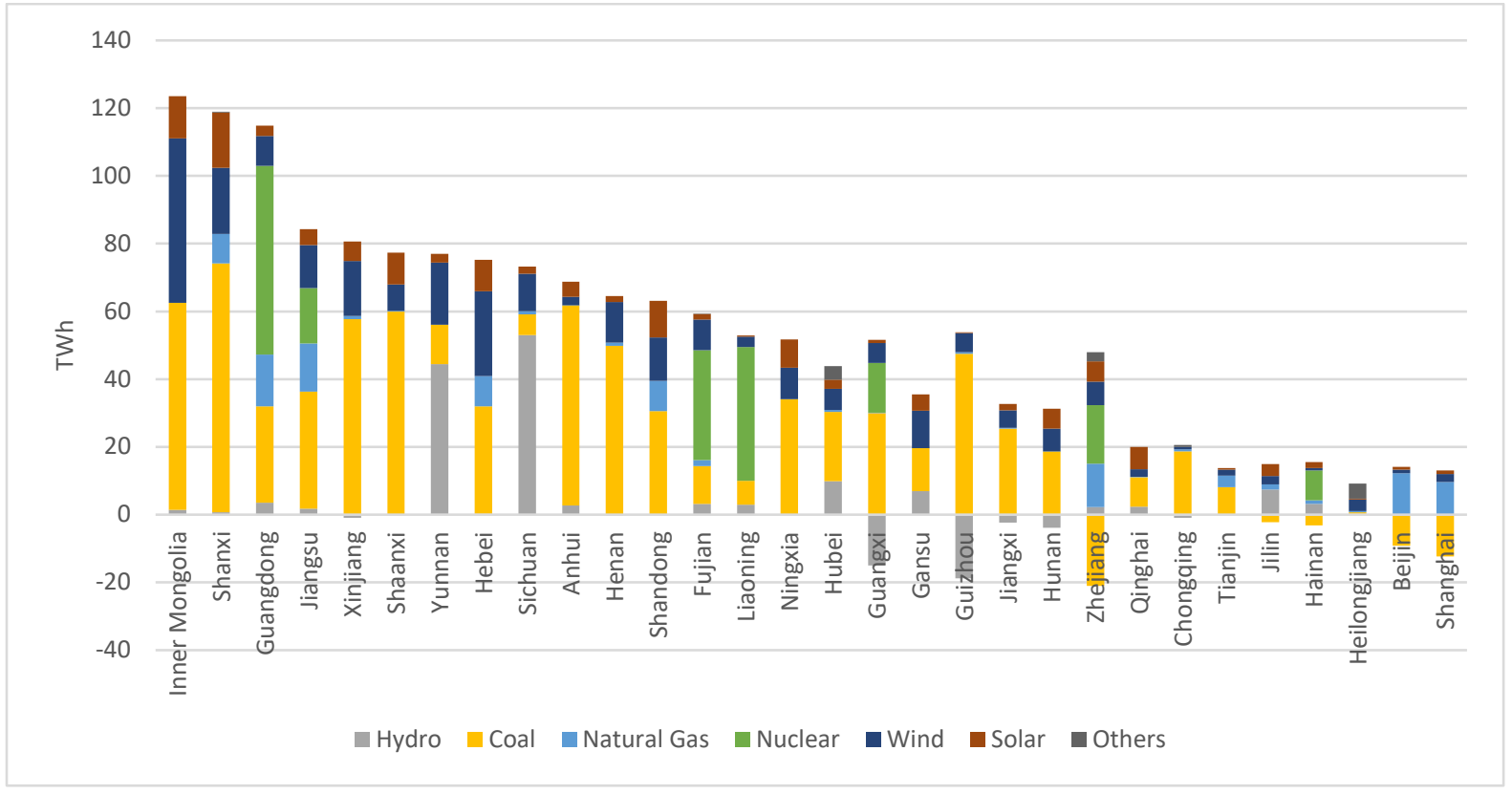

Figure 5: Growth of each power generation technology between 2015 and 2020

Figure 5 shows the contribution of each power generation technology to the growth in total power generation in all provinces. In most provinces, coal power is still the most important growth contributor for power generation in 2020. It coincides with the increasing coal capacity, an addition of 87 GW of coal fleet from 939 GW in 2015 to 1026 GW in 2020. Several provinces experience decline in coal power generation, including Zhejiang, Jilin, Hainan, Beijing and Shanghai. The decline will be replaced by different sources at different locations. For example, coastal affluent areas will see the replacement by natural gas (in Beijing, Shanghai and Zhejiang); Hainan will see a large increase in nuclear power, while Jilin shows an increase in hydropower generation. Sichuan and Yunnan show significant increase in hydropower generation, with the expansion of hydropower capacity in these provinces. On the other hand, a decrease in hydropower generation is mostly due to the differences in operating hours in Guangxi and Guizhou. Operating hours in 2015 are higher than in previous years. In fact, NEA [38] shows that the operating hours dropped slightly in most provinces in 2016 (e.g. in Guizhou, operating hours declined from 4,012 hours in 2015 to 3,315 hours in 2016; and Guangxi showed a decline from 4,632 to 3,802 hours between 2015 and 2016). The high 
hydropower operating hours in 2015 were triggered by unusually increased precipitation, which is not a regular phenomenon in these regions. Together with limited hydropower capacity addition, hydropower generation is likely to decline in these provinces. Non-hydro renewable energy such as wind and solar starts to contribute to the generation growth, noticeably in provinces such as Inner Mongolia, Hebei, and Shanxi which have ambitious wind and solar capacity targets. Inner Mongolia, for instance, will see the largest increase in power generation growth (123 TWh in total). Wind and solar together will contribute to $49 \%$ of the growth, which is equivalent to the growth in coal power generation.

With the nuclear capacity under construction, Guangdong, Liaoning and Fujian are expected to see a large amount of new nuclear power generation. Nevertheless, the contribution of nuclear power generation to the total power generation is still small due to the large total power generation. Nevertheless, the overall level of emissions will remain on a growing trend, despite a decline in carbon intensity in most provinces.

\subsection{A comparison with previous studies}

Several studies address the power sector carbon intensity from different perspectives. Some address the total power sector emissions at provincial level. For example, Lindner et al. [39] compare the production and consumption-based $\mathrm{CO}_{2}$ emissions from power sector in China's provinces. The study shows that a significant amount of $\mathrm{CO}_{2}$ emissions is embodied in electricity imports/exports among provinces. Similar results can also be found in $\mathrm{Ma}$ and $\mathrm{Ge}$ [40]. Inner Mongolia demonstrates $109 \mathrm{Mt} \mathrm{CO}_{2}$ emission reduction due to large amounts of electricity exports. On the other hand, Beijing shows a $60 \mathrm{Mt}$ or $320 \%$ emissions increase due to its reliance on electricity imports. Despite the differences in total emissions, the carbon intensity of power production does differ substantially when power trade is considered. There are several reasons: firstly, it is difficult to identify power trade sources. In most cases, average emission factor in each province are used to represent the emission factors of power imports. Indeed, there is no large variations on power mix in China, with exceptions in the western/central China which has large-scale hydropower generation. Secondly, for the reason above, net exporting provinces do not show great differences, except from those which also import electricity from other provinces (provinces usually both import and export electricity for power grid operational purposes). At last, for most provinces the amount of power trade among provinces is small comparing to their total consumption. Beijing and Shanghai are two exceptions due to limited self-producing capability.

To the best of our knowledge, very few studies address the future carbon intensity of power generation in China at provincial level. Some studies address the issue in the past. For example, Qu et al. [41] estimate the carbon intensity of electricity generation at provincial level in 2013. Comparing with our results, provincial emission factors in Qu et al.'s research is much higher (See Figure S1 in appendix). This is mainly due to the differences in power generation mix. For example, in Liaoning, coal power accounted for $84 \%$ of total power generation in 2013, comparing to $65 \%$ in 2020 due to the growth in nuclear power generation. In another study, Ou et al. [42] project the carbon intensity of power generation at national level in 2020 from a 
life cycle perspective. The studies includes three scenarios which represent different share of power generation technologies in the power mix. The share of power generation in the business-as-usual scenario is close to our estimation (with $70 \%$ coal, $1.8 \%$ oil, $0.7 \%$ natural gas, $5 \%$ nuclear, $0.5 \%$ biomass, $1.9 \%$ Wind and Solar, and $20 \%$ hydro). It concludes that the carbon intensity of power generation will reach $917 \mathrm{~g} / \mathrm{kWh}$ under the BAU scenario. The result is much higher than our estimation since the estimated life cycle GHG emissions for coal is close to $1,100 \mathrm{~g} \mathrm{CO}_{2}$-e/kWh. The value is $20 \%$ higher than the value used in this research.

\section{Discussion}

The carbon intensities of power generation in most provinces are within the 500 to 700 grams per kWh range by 2020. This means that the process of electrification can be carbon competitive from the perspective of electricity generation. Nevertheless, continuous efforts are needed in order to fulfil the longer-term target since coal is still a major contributing factor to the growth of power generation in the near future. Given that the lifespan of coal-fired power plants is usually between 35 and 40 years, it is important to address the role of coal power generation in the power system sooner rather than later. There is growing consensus in the scientific community $[43,44]$ and among policy makers that achieving the central aim of the Paris Agreement requires an early capping and then a rapid decline in global unabated coalfired power generation. This implies shutting down many existing coal power plants. Robinson and $\mathrm{Li}$ [45] introduce the international experiences of phasing out coal power and discuss the implications to China's coal power sector. The authors suggest several ideas that can help China to accelerate the phasing-out of coal power generation. These include providing longterm credible policy signals to investors, creation of competitive electricity market mechanism, internalizing environmental externalities, improvement of the electricity sector governance, and exploring opportunities associated with the transition away from coal. One other option is to retrofit existing plants with carbon capture and storage (CCS) and requiring CCS or similar abatement on new plants. In China, the growing demand of electricity might imply the operation of coal power plants in the near future therefore, large-scale shutting down of coal power plants is not a straight-forward option. To this end, CCS will need to play a central role in reducing carbon intensity in China in the longer term. Given the significance of CCS in addressing climate change targets in China, government support is necessary to encourage research and development of CCS technologies, which should be implemented sooner rather than later.

For provinces with very high level of coal power generation, coordination is key to achieve a longer-term target. There are always restrictions on the choice of power generation technologies: some are due to resource endowments; others depend on political constrains. In those provinces with very high proportion of electricity provided by coal, there are limited choices to the selection of other power generation technologies. Better coordination among provinces is needed to fully exploit the benefits of renewable energy development in resourcerich regions and reduce carbon intensity of power generation in those constrained provinces. 
Instead of a legal binding emission standard, China has been emphasizing the energy efficiency in coal-fired power generation. Coal consumption per unit of power generation (or power supply) is regulated for both existing and new coal power plants. Addressing air pollutants, the Large Combustion Plan Directive [46] and the Industrial Emission Directive [47] set emission standards for power stations in the EU. Owners of power stations can opt to comply with these standards or opt out, in which case the plants would have to close. By 2009, a total of 205 power plants in 17 EU countries had opted out [48]. Nevertheless, these power plants were given sufficient time to make a decision which effectively ease the transition. We would encourage the continuous measures on energy efficiency given that coal will still be the major power generation source in the coming years. In addition, sufficient notice should be given in order to smooth the process of compliance.

The improvement of the operating hours for renewable energy sources is also an important element. There are several different ways to promote the use of renewable energy sources in the competition with conventional fossil-fuel based generation. For example, carbon pricing can make carbon-intensive generation uncompetitive. China has announced the establishment of the national cap-and-trade carbon trading system on December 2017 [22]. Electricity and heat generation is the only industry that is covered at the initial stage under the system. It covers over $70 \%$ of the total emissions from the power system, which amount to more than 3,500 million tonnes of $\mathrm{CO}_{2}$. Carbon pricing proves to be more cost-effective than subsidies to renewable energy sources [49]. However, the effectiveness of carbon pricing is dependent on the price sensitivity of the industry. It can be ineffective if the price is so low that it only has marginal impacts on the competitiveness of fossil-fuel based generation; it can also be worrisome if carbon price becomes too high and result in unwillingness of power generation from coal-fired plants. A successful example is the carbon floor price in the UK, which accelerated the phase-out of coal power generation due to lack of competitiveness [50]. Therefore, a systematic review on the potential impacts of carbon pricing on coal power generation at provincial level is needed. Nevertheless, China should consider a boarder scope of emission trading system. Focusing on one particular industry may encourage the use of fossil fuels in other industries. For example, between 2012 and 2015, total emissions in New York State increased by $4 \%$ since the implementation of the Regional Greenhouse Gas Initiative cap and trade programme. The programme addressed emission reduction from power sector in particular, which had led to a $10 \%$ emission reduction in the sector. However, emission levels had increased significantly in heating and transportation during the same period [51].

In addition, a liberalised electricity market can make use of competitive market mechanisms to support least cost dispatch, retail competition, regional power exchange and so on. Such market-based mechanisms can support the integration of renewable energy sources, which usually have close to zero marginal cost. China had started its power system reform since the early 2000s, though the system is still very rigid in ways that favour incumbent coal and discourage competition from renewables. The increasing contribution of renewables (with fewer curtailments) can effectively reduce carbon intensity of power generation. Certainly, sustainable electricity sector planning needs to consider a wider range of parameters and embed 
effective climate change targets [52]. Domestically, there is clear trend that China is moving away from coal-fired based power generation to a low-carbon power generation pathway. In this trajectory China will reduce its power sector carbon intensity and will have significant impact on the global carbon and fossil fuel markets and renewable energy industry in the longer term. Internationally, China has been promoting the Belt and Road Initiative (BRI). With the implementation of BRI, China will provide financial as well as technical support to the countries alongside the BRI in their infrastructure construction. One of the core elements in the BRI is the energy infrastructure. China has proposed to promote the use of advanced coal power technology in the region covered by the BRI [53]. However, a number of countries and international organizations have announced plans to move away from coal. The potential environmental consequences and risk of stranded assets for investors should be fully addressed before making final investment decisions.

At last, research and development on other renewable energy enabling technologies, such as energy storage system, is also necessary. The development of energy storage can assist the growth of renewable energy and improve emissions management [54] as well as boosting the local economy by creating new jobs and increasing local GDP.

\section{Conclusion}

In this study, we estimate the carbon intensities of power generation in China's provinces. We find that most provinces are expected to have a carbon intensity per unit of power generation between 500 and 700 grams/kWh in 2020, which justifies the progress of electrification from the power generation perspective. Coal is still a major contributor to the increasing power generation in most provinces. Given the global trend of phasing out coal in order to reduce GHG emissions, China's provinces should consider measures that can help to reduce emissions from coal power generation gradually. At the same time, renewable energy sources are becoming increasingly important, especially in the western and northern provinces which have large renewable energy potentials. Renewable energy sources can help reduce the carbon intensity of power generation, but it has experienced significant curtailments. To increase the contribution of renewable energy to total power generation, it requires a better coordination among provinces and relevant government support.

In this research, we use the emission factors from IPCC to estimate the range of emissions in China's provinces. Although IPCC data is reliable, it might noy represent the status quo in different provinces. As was mentioned in Section 3, the use of hybrid life cycle analysis can capture both the upstream and downstream emissions hence have a relatively complete system boundary. Further research should incorporate such analysis in order to make the results more representative for each province.

\section{References}


1. Chalvatzis, K.J. and K. Rubel, Electricity portfolio innovation for energy security: The case of carbon constrained China. Technological Forecasting and Social Change, 2015. 100: p. 267276.

2. Chalvatzis, K.J. and A. Ioannidis, Energy Supply Security in Southern Europe and Ireland. Energy Procedia, 2017. 105: p. 2916-2922.

3. Chalvatzis, K.J. and A. Ioannidis, Energy supply security in the EU: Benchmarking diversity and dependence of primary energy. Applied Energy, 2017. 207(Supplement C): p. 465-476.

4. Kennedy, C.A., N. Ibrahim, and D. Hoornweg, Low-carbon infrastructure strategies for cities. Nature Climate Change, 2014. 4: p. 343.

5. Kennedy, C., Key threshold for electricity emissions. Nature Clim. Change, 2015. 5(3): p. 179181.

6. IEA, Energy Technology Perspectives 2014: Harnessing Electricity's Potential. 2014, International Energy Agency: Paris.

7. UK GOV, Carbon price floor: reform, H.R. Customs, Editor. 2014: UK.

8. IEA, Coal Medium-Term Market Report: Market Trends and Projections to 2017. 2012, International Energy Agency: Paris, France.

9. Hofmann, J., et al., Assessment of electrical vehicles as a successful driver for reducing CO2 emissions in China. Applied Energy, 2016. 184: p. 995-1003.

10. Zafirakis, D., et al., The Multiple Role of Energy Storage in the Industrial Sector: Evidence from a Greek Industrial Facility. Energy Procedia, 2014. 46: p. 178-185.

11. State Council. The Thirteenth Five Year Plan on Controlling Greenhouse Gas Emissions. 2016 [cited 2017 [in Chinese] 16 June ]; Available from: http://www.gov.cn/zhengce/content/201611/04/content_5128619.htm

12. Pappas, D. and K.J. Chalvatzis, Energy and Industrial Growth in India: The Next Emissions Superpower? Energy Procedia, 2017. 105: p. 3656-3662.

13. Chalvatzis, K.J., Electricity generation development of Eastern Europe: A carbon technology management case study for Poland. Renewable and Sustainable Energy Reviews, 2009. 13(6): p. 1606-1612.

14. Kaldellis, J.K., G. Spyropoulos, and K.J. Chalvatzis, The impact of Greek electricity generation sector on the national air pollution problem. Fresenius Environmental Bulletin, 2004. 13(7): p. 647-656.

15. Li, X., K. Hubacek, and Y.L. Siu, Wind power in China - Dream or reality? Energy, 2012. 37(1): p. 51-60.

16. NDRC, The 13th Five-Year Plan For Economic and Social Development of the People's Republic of China, Central Comittee of the Communist Party of China, Editor. 2016: Beijing, China.

17. Kaldellis, J.K. and K.J. Chalvatzis, Environment and Industrial Development: Sustainability and Development, Air Pollution. 2005: Stamoulis Publications.

18. Rutter, R., et al., Branding Instead of Product Innovation: A Study on the Brand Personalities of the UK's Electricity Market. European Management Review, 2017. ISSN 1740-4754.

19. NDRC, Thirteen Five Year Plan on Electricity System Development, National Development and Reform Commission and National Energy Administration, Editors. 2016: Beijing.

20. IEA, World Energy Outlook 2017. 2017: OECD Publishing/IEA.

21. Xinhua. The lanuch of national carbon trading scheme, how does it look like? . 2017 [cited 2017 [in Chinese] 29 December ]; Available from: http://news.xinhuanet.com/fortune/201712/20/c_1122137497.htm.

22. NDRC. Press realise on the launch of carbon trading scheme in China by the National Development and Reform Commission. 2017 [cited 2017 [in Chinese] 29 December]; Available from: http://www.ndrc.gov.cn/xwzx/xwfb/201712/t20171219_871028.html.

23. Reuters. China extends tax rebate for electric cars, hybrids. 2017 [cited 201729 December]; Available from: https://www.reuters.com/article/us-china-autos-tax/china-extends-tax-rebatefor-electric-cars-hybrids-idUSKBN1EL0EV. 
24. Pothitou, M., R.F. Hanna, and K.J. Chalvatzis, ICT entertainment appliances' impact on domestic electricity consumption. Renewable and Sustainable Energy Reviews, 2017. 69: p. 843-853.

25. Pothitou, M., R.F. Hanna, and K.J. Chalvatzis, Environmental knowledge, pro-environmental behaviour and energy savings in households: An empirical study. Applied Energy, 2016. 184: p. 1217-1229.

26. Shearer, C., R. Fofrich, and S. Davis, Future CO2 emissions and electricity generation from proposed coal - fired power plants in India. Earth's Future, 2017. 5(4): p. 408-416.

27. $\quad$ Endcoal. Proposed Coal Plants in China - July 2017. 2017 [cited 20171 November 2017]; Available from: https://endcoal.org/wp-content/uploads/2017/07/PDFs-for-GCPT-July-2017China-MW.pdf.

28. NEA. Statistics on solar power in China. 2017 [cited 2017 [in Chinese] 16 June]; Available from: http://www.nea.gov.cn/2017-02/04/c_136030860.htm.

29. China Electricity Council. 2017 electric power industry summary statistics (2017 年全国电力 工业统计数据). 2018; Available from: https://chinaenergyportal.org/en/2017-electric-powerindustry-summary-statistics/

30. National Energy Administration, Notice on publication of the "Measures for resolving curtailment of hydro, wind and PV power generation" 国家发展改革委 国家能源局关于印 发《解决弃水弃风弃光问题实施方案》的通知, National Development and Reform Commission, Editor. 2017: Beijing.

31. NEA, Wind Power Integration and Operation in 2017, National Energy Administration, Editor. 2017: Beijing.

32. Feng, K., et al., The energy and water nexus in Chinese electricity production: A hybrid life cycle analysis. Renewable and Sustainable Energy Reviews, 2014. 39: p. 342-355.

33. Li, X., et al., Challenges faced when energy meets water: $\mathrm{CO} 2$ and water implications of power generation in inner Mongolia of China. Renewable and Sustainable Energy Reviews, 2015. 45: p. 419-430.

34. Li, X., et al., Energy-water nexus of wind power in China: The balancing act between CO 2 emissions and water consumption. Energy Policy, 2012. 45: p. 440-448.

35. IPCC. Technology-specific Cost and Performance Parameters. 2014; Available from: https://www.ipcc.ch/pdf/assessment-report/ar5/wg3/ipcc_wg3_ar5_annex-iii.pdf?

36. Kennedy, C., Key threshold for electricity emissions. Nature Climate Change, 2015. 5: p. 179.

37. Liu, Z., et al., Reduced carbon emission estimates from fossil fuel combustion and cement production in China. Nature, 2015. 524: p. 335.

38. NEA. Statistics on power plant (larger than 6 MW) operating hours in 2016. 2017 [cited 2017 [in Chinese] 16 June ]; Available from: http://www.nea.gov.cn/2017-01/26/c_136014619.htm.

39. Lindner, S., et al., CO2 emissions from China's power sector at the provincial level: Consumption versus production perspectives. Renewable and Sustainable Energy Reviews, 2013. 19(Supplement C): p. 164-172.

40. Ma, C.-M. and Q.-S. Ge, Method for Calculating CO2 Emissions from the Power Sector at the Provincial Level in China. Advances in Climate Change Research, 2014. 5(2): p. 92-99.

41. Qu, S., S. Liang, and M. Xu, CO2 Emissions Embodied in Interprovincial Electricity Transmissions in China. Environmental Science \& Technology, 2017. 51(18): p. 10893-10902.

42. Ou, X., Y. Xiaoyu, and X. Zhang, Life-cycle energy consumption and greenhouse gas emissions for electricity generation and supply in China. Applied Energy, 2011. 88(1): p. 289-297.

43. Pfeiffer, A., et al., The ' $2{ }^{\circ} \mathrm{C}$ capital stock' for electricity generation: Committed cumulative carbon emissions from the electricity generation sector and the transition to a green economy. Applied Energy, 2016. 179(Supplement C): p. 1395-1408.

44. Davidson, O., et al., New unabated coal is not compatible with keeping global warming below $2{ }^{\circ}$ C. Statement by leading climate and energy scientists. 2013, European Climate,.

45. Robinson, D. and X. Li, Closing Coal in China: International experiences to inform power sector reform, in Working Paper. 2017, Smith School of Enterprise and the Environment, University of Oxford. 
46. European Commission, Large Combustion Plants Directive, in Directive 2001/80/EC, European Parliament and the Council of the European Union, Editor. 2001.

47. European Commission, Industrial Emissions Directive, in Directive 2010/75/EU, European Parliament and the Council of the European Union, Editor. 2010.

48. Harrison, P. UK and Poland top dirty coal list, closures loom. 2009 [cited 201729 December]; Available from: https://uk.reuters.com/article/eu-energy-coal/uk-and-poland-top-dirty-coallist-closures-loom-idUKLC81083120090213.

49. Bassi, S., et al., Credible, effective and publicly acceptable policies to decarbonise the European Union. 2017, Grantham Research Institute on Climate Change and the Environment: London.

50. Hirst, D., Carbon Price Floor (CPF) and the price support mechanism, in Briefing Paper. 2017, House of Commons,.

51. Kaufman, N. and J. Elkind, Can China's CO2 Trading System Avoid the Pitfalls of Other Emissions Trading Schemes? 2018, Center on Global Energy Policy.

52. Malekpoor, H., et al., Integrated Grey Relational Analysis and Multi Objective Grey Linear Programming for Sustainable Electricity Generation Planning. Annals of Operations Research, 2017. ISSN 0254-5330(in press).

53. Sandalow, D. and Q. Xu, Global Energy Dialogue: Belt and Road Initiative Green Development Conference. 2017, Columbia University and Renmin University: New York City.

54. Zafirakis, D., K.J. Chalvatzis, and G. Baiocchi, Embodied CO2 emissions and cross-border electricity trade in Europe: Rebalancing burden sharing with energy storage. Applied Energy, 2015. 143: p. 283-300. 
Appendix

Table S1 Power generating capacity in 2020

\begin{tabular}{|c|c|c|c|c|c|c|c|c|}
\hline & Hydro & Coal & $\begin{array}{l}\text { Natural } \\
\text { Gas }\end{array}$ & Nuclear & Wind & Solar & Others & Total \\
\hline National & 358,697 & $1,025,811$ & 109,921 & 51,474 & 205,000 & 156,802 & 18,630 & 1,926,335 \\
\hline Beijin & 980 & - & 9,944 & - & 650 & 1,000 & 350 & 12,924 \\
\hline Tianjin & 10 & 11,872 & 5,370 & - & 1,000 & 800 & 20 & 19,072 \\
\hline Hebei & 1,820 & 46,186 & 4,000 & - & 21,000 & 15,000 & 800 & 88,806 \\
\hline Shanxi & 2,500 & 66,448 & 7,000 & - & 16,000 & 12,000 & 500 & 104,448 \\
\hline Inner Mongolia & 2,380 & 82,700 & - & - & 45,000 & 15,000 & 240 & 145,320 \\
\hline Liaoning & 2,930 & 31,773 & - & 7,652 & 8,000 & 520 & 790 & 51,665 \\
\hline Jilin & 6,450 & 16,091 & 900 & - & 5,500 & 2,400 & 1,130 & 32,471 \\
\hline Heilongjiang & 1,020 & 19,348 & 613 & - & 6,000 & 170 & 1,100 & 28,250 \\
\hline Shanghai & - & 14,310 & 8,000 & - & 1,400 & 800 & 10 & 24,520 \\
\hline Jiangsu & 2,600 & 77,888 & 20,000 & 4,250 & 10,000 & 8,000 & 1,500 & 124,238 \\
\hline Zhejiang & 11,970 & 42,480 & 12,500 & 9,070 & 4,000 & 8,000 & 1,100 & 89,120 \\
\hline Anhui & 5,030 & 51,260 & 40 & - & 2,600 & 8,000 & 2,000 & 68,930 \\
\hline Fujian & 13,350 & 26,648 & 3,860 & 8,710 & 5,000 & 900 & 500 & 58,968 \\
\hline Jiangxi & 4,900 & 22,798 & 389 & - & 3,670 & 3,435 & 560 & 35,752 \\
\hline Shandong & 1,077 & 94,902 & 4,000 & 2,700 & 14,000 & 10,000 & 2,300 & 128,979 \\
\hline Henan & 3,990 & 65,385 & 1,357 & - & 6,000 & 2,840 & 1,600 & 81,172 \\
\hline Hubei & 38,600 & 28,725 & 853 & - & 5,000 & 3,500 & 1,000 & 77,678 \\
\hline Hunan & 15,340 & 22,564 & 3 & - & 6,000 & 2,000 & 360 & 46,267 \\
\hline Guangdong & 13,550 & 61,682 & 23,958 & 15,616 & 6,000 & 6,000 & 230 & 127,036 \\
\hline Guangxi & 17,250 & 19,999 & 287 & 2,176 & 3,400 & 1,022 & 350 & 44,484 \\
\hline Hainan & 1,500 & 3,474 & 1,713 & 1,300 & 650 & 1,250 & 150 & 10,037 \\
\hline Chongqing & 6,760 & 14,780 & 824 & - & 500 & 5 & 130 & 22,999 \\
\hline Sichuan & 83,010 & 13,915 & 1,522 & - & 6,000 & 2,500 & 620 & 107,567 \\
\hline Guizhou & 20,560 & 33,710 & 738 & - & 6,000 & 460 & 150 & 61,618 \\
\hline Yunnan & 70,000 & 12,835 & - & - & 12,000 & 2,080 & - & 96,915 \\
\hline Shaanxi & 2,660 & 37,710 & 270 & - & 5,500 & 7,000 & 480 & 53,620 \\
\hline Gansu & 9,500 & 20,285 & 119 & - & 14,000 & 11,000 & 380 & 55,284 \\
\hline Qinghai & 11,450 & 4,150 & 198 & - & 2,000 & 10,000 & - & 27,798 \\
\hline Ningxia & 430 & 24,370 & - & - & 9,000 & 8,000 & 30 & 41,830 \\
\hline Xinjiang & 5,730 & 57,525 & 1,463 & - & 18,000 & 8,620 & 250 & 91,588 \\
\hline
\end{tabular}

Table S2 operating hours in 2020 


\begin{tabular}{|c|c|c|c|c|c|c|c|}
\hline & Hydro & Coal & Natural Gas & Nuclear & Wind & Solar & Others \\
\hline National & 3343.4 & 4617.5 & 2486.8 & 7058.7 & 1807.7 & 1055.7 & 1035.9 \\
\hline Beijing & 700.6 & 4464.3 & 4459.8 & 0.0 & 2133.3 & 800.0 & 1035.9 \\
\hline Tianjin & 1500.0 & 4954.3 & 2246.7 & 0.0 & 2434.8 & 659.6 & 1035.9 \\
\hline Hebei & 714.2 & 5246.2 & 2246.7 & 0.0 & 2077.0 & 734.6 & 1035.9 \\
\hline Shanxi & 1522.7 & 4490.0 & 2246.7 & 0.0 & 1936.0 & 1428.6 & 105.3 \\
\hline Inner Mongolia & 2129.7 & 4874.7 & 0.0 & 0.0 & 1986.0 & 1211.5 & 1035.9 \\
\hline Liaoning & 2078.7 & 4406.4 & 0.0 & 7058.7 & 1929.0 & 1000.0 & 1035.9 \\
\hline Jilin & 1963.7 & 3500.7 & 2246.7 & 0.0 & 1535.8 & 1492.5 & 1035.9 \\
\hline Heilongjiang & 2117.8 & 4126.9 & 2246.7 & 0.0 & 1765.3 & 1818.2 & 800.0 \\
\hline Shanghai & 0.0 & 4214.6 & 2246.7 & 0.0 & 2406.3 & 1428.6 & 1035.9 \\
\hline Jiangsu & 1145.8 & 5380.2 & 2246.7 & 7738.3 & 1980.0 & 976.7 & 1035.9 \\
\hline Zhejiang & 2101.5 & 4374.4 & 2246.7 & 7374.2 & 2161.0 & 833.3 & 1000.0 \\
\hline Anhui & 1520.7 & 5030.9 & 2246.7 & 0.0 & 2109.0 & 600.0 & 1035.9 \\
\hline Fujian & 3528.9 & 4319.6 & 2246.7 & 7058.7 & 2682.9 & 2000.0 & 50.0 \\
\hline Jiangxi & 3006.2 & 4581.3 & 2246.7 & 0.0 & 2114.0 & 625.0 & 1035.9 \\
\hline Shandong & 526.4 & 5046.6 & 2246.7 & 7058.7 & 1869.0 & 1142.9 & 1035.9 \\
\hline Henan & 2669.5 & 4453.3 & 2246.7 & 0.0 & 2200.0 & 759.8 & 1035.9 \\
\hline Hubei & 3631.5 & 4251.5 & 2246.7 & 0.0 & 2063.0 & 833.3 & 800.0 \\
\hline Hunan & 3139.4 & 3975.3 & 2246.7 & 0.0 & 2125.0 & 3000.0 & 1035.9 \\
\hline Guangdong & 2354.7 & 4463.4 & 2246.7 & 7451.8 & 2162.2 & 567.3 & 1035.9 \\
\hline Guangxi & 3561.0 & 4195.4 & 2246.7 & 7058.7 & 2365.0 & 888.9 & 1035.9 \\
\hline Hainan & 2700.7 & 5016.9 & 2246.7 & 7058.7 & 2120.0 & 1500.0 & 1035.9 \\
\hline Chongqing & 3244.0 & 4223.7 & 2246.7 & 0.0 & 2000.0 & 1055.7 & 1000.0 \\
\hline Sichuan & 3971.8 & 3347.7 & 2246.7 & 0.0 & 2247.0 & 925.9 & 1035.9 \\
\hline Guizhou & 3107.6 & 4549.0 & 2246.7 & 0.0 & 1806.0 & 666.7 & 1035.9 \\
\hline Yunnan & 3744.0 & 3061.8 & 0.0 & 0.0 & 2315.2 & 1500.0 & 1035.9 \\
\hline Shaanxi & 3080.7 & 4801.6 & 2246.7 & 0.0 & 1951.0 & 1428.6 & 0.0 \\
\hline Gansu & 4262.7 & 4096.5 & 2246.7 & 0.0 & 1695.6 & 969.5 & 0.0 \\
\hline Qinghai & 3444.3 & 4914.1 & 2246.7 & 0.0 & 1726.0 & 1411.3 & 0.0 \\
\hline Ningxia & 4008.9 & 5602.6 & 0.0 & 0.0 & 2009.9 & 1493.7 & 0.0 \\
\hline Xinjiang & 3384.8 & 4555.2 & 2246.7 & 0.0 & 1742.9 & 1337.0 & 0.0 \\
\hline
\end{tabular}




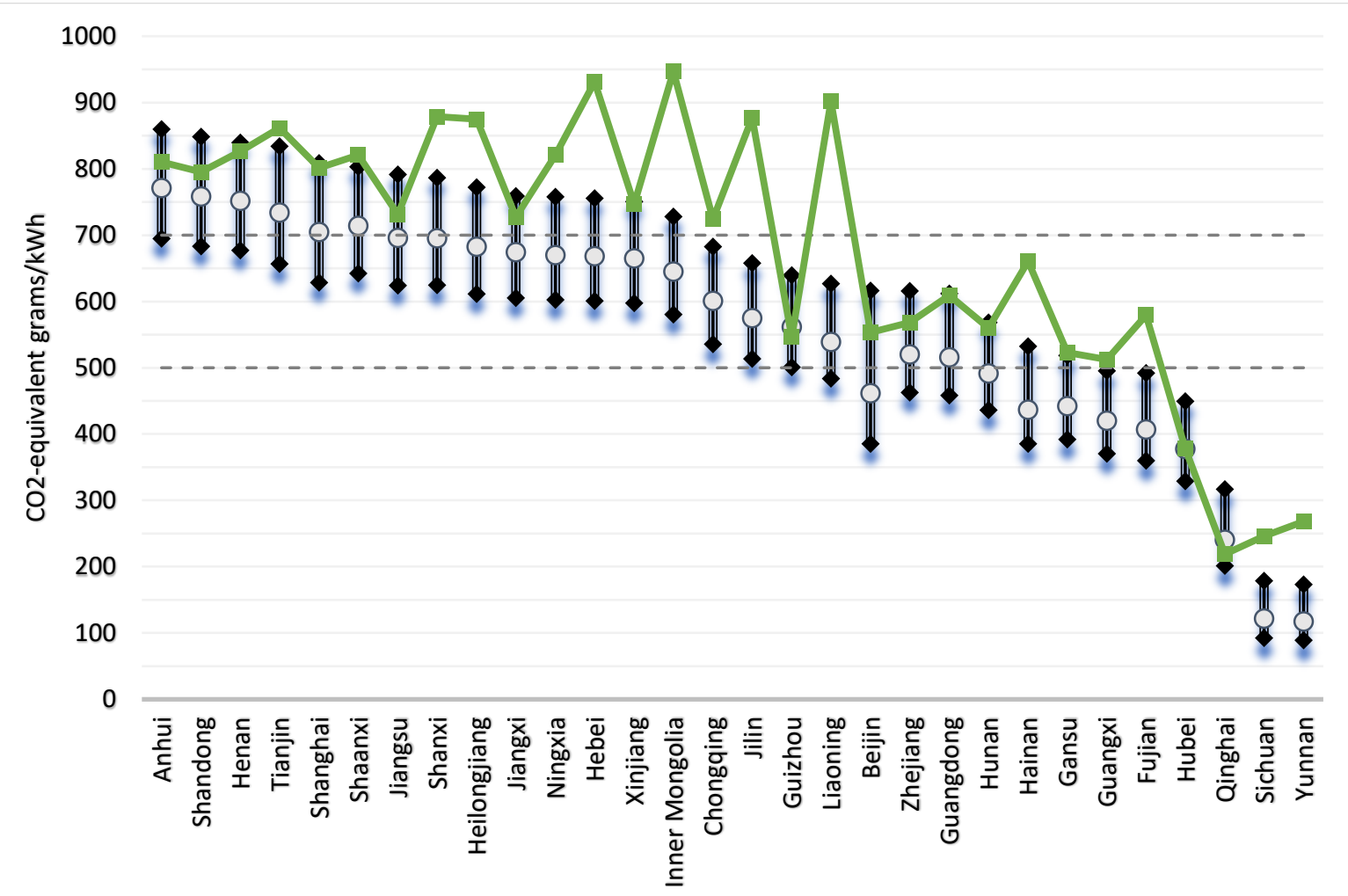

Figure S1 A comparison with results from Qi et al. (2017) 